\title{
The use of ultrasound-guided cardiac assessment in the anesthetic management for emergent noncardiac surgical patients
}

\author{
Caron M. Hong ${ }^{1 *}$, Samuel M. Galvagno ${ }^{2}$ and Sarah B. Murthi ${ }^{3}$ \\ *Correspondence: chong@anes.umm.edu \\ CrossMark \\ $\leftarrow$ Click for updates
}

\begin{abstract}
'Department of Anesthesiology, Division of Critical Care Medicine, University of Maryland School of Medicine, Baltimore, Maryland, USA. 2Department of Anesthesiology, Division of Trauma Anesthesiology, Division of Critical Care Medicine, University of Maryland School of Medicine, Baltimore, Maryland, USA.

${ }^{3}$ Department of Surgery, Division of Trauma and Critical Care Medicine, University of Maryland School of Medicine, Baltimore, Maryland, USA.
\end{abstract}

\begin{abstract}
Background: Hemodynamic monitoring is essential in emergent noncardiac surgery. The majority of reports investigate the use of transesophageal echocardiography with beneficial results. However, this requires expertise and is associated with complications. The use of an intraoperative diagnostic cardiac ultrasound is noninvasive and can provide real-time information, in the intraoperative period, and assist in decision-making by anesthesiologists especially during hemodynamic instability.

Methods: This retrospective case series of six (6) patients describes the utility of a diagnostic intraoperative cardiac ultrasound, performed by anesthesiologists, in emergent noncardiac surgical patients. The ultrasound consisted of four standard windows: the parasternal long axis (PLA), parasternal short axis (PSA), apical (AP) and sub-xyphoid (SX) views. These views were used to assess basic findings including left ventricular function, right atrial function, right ventricular function, and overall volume status and volume responsiveness.

Results: This case series included six emergent noncardiac surgical patients, including trauma, general, neurosurgical and orthopedic patients. The patients were between the ages of 29 to 87 years old with an equal distribution of males and females. Information from the cardiac ultrasound exams were used to assist in decisions for induction of anesthesia, level of resuscitation, inotropic or vasopressor initiation and etiology of cardiac arrest.
\end{abstract}

Conclusion: A diagnostic cardiac ultrasound is a rapid non-invasive tool that, when used by experienced anesthesiologists, provide real-time information that help guide intraoperative patient care and may ultimately improve outcome.

Keywords: Intraoperative care, diagnostic cardiac ultrasound, emergent noncardiac surgery, hemodynamic monitoring

\section{Introduction}

In the United States, $40 \%$ of surgical patients will present with, or be at risk for coronary artery disease $[1,2]$. Utilization of tools to improve care of this large sector of our surgical population is essential. Perioperative echocardiography has been shown to assist in the diagnosis and management of hemodynamic instability in high-risk cardiac and noncardiac surgical procedures [3-8]. Transesophageal echocardiography (TEE) has demonstrated to change therapy more than $40 \%$ intraoperatively [8]. TEEs are efficacious in determining overall cardiac function and possible etiologies of hemodynamic instability in the perioperative period. However, TEE requires a unique level of training and expertise. Therefore, there are limitations in regards to availability of trained staff to complete and assess the examination intraoperatively during acute decompensation events. Moreover, TEE is invasive and associated with major 
complications including esophageal and gastric perforation as well as dysphagia $[\mathbf{9 , 1 0 ]}$. Cardiac ultrasound has become popular in critical care since this modality presents minimal to no risk to the patient and growing cohorts of clinicians have attained competence to perform and interpret the examination. Its use has more than doubled within the last decade [11], however its use in the intraoperative period has only recently been explored. A few studies from Australia have investigated perioperative TTE and TEE and assess anesthesiologists with advanced training in TEE and cardiac $[12,13]$. Regardless, they did demonstrate its use in the perioperative period is valuable in the care of patients. Diagnostic TTE has been shown to assist in the management of the critically ill, the acutely ill and burn patients [14-18]. Utilizing a diagnostic cardiac ultrasound has been shown to change acute care in the critically ill by more than 50\% [19]. An anesthesiologist, not specifically trained in cardiac or advanced TEE, can utilize a cardiac ultrasound as a tool in the intraoperative period to assist in the care of emergent noncardiac surgical patients by providing essential real-time information that could change care and may improve patient outcomes.

The cardiac parameters that are useful in emergent noncardiac surgical patients is overall left ventricular (LV) and right ventricular (RV) function, general valvular function and overall volume status. This information can be utilized prior to induction and during the surgical procedure, particularly during hemodynamic instability. Echocardiographic examinations, aside from providing a real-time picture of cardiac function and volume status, can evaluate the response to management such as fluids, vasopressors, inotropes or vasodilators. The current standard for monitoring intraoperative hemodynamic instability is invasive monitors, such as arterial catheters and pulmonary artery catheters (PAC). These modalities have been used, along with standard monitors (including non-invasive blood pressure, electrocardiography and pulse oximetry), to provide essential real-time physiologic information. Nevertheless, due to the invasive nature of these monitors, there are associated complications. Therefore, there is a niche for noninvasive tools, such as cardiac ultrasound, that can provide the same information with no risk to the patient that can be utilized by an experienced general anesthesiologist. Moreover, diagnostic cardiac ultrasounds have been found to retrieve similar physiological findings as PACs [20]. A focused rapid cardiac ultrasound can be an intraoperative tool to assist in the management and care of patients undergoing noncardiac surgery $[3,21]$ and can change care [2].

This case series describes the utility of a diagnostic cardiac ultrasound examination in the intraoperative period in emergent noncardiac surgical patients and directly assist in the management of resuscitation and vasoactive medications. We have an established program for training physicians of multiple disciplines (including anesthesiology, surgery, emergency medicine and internal medicine) in performing and assessing these cardiac ultrasound examinations. We have a number of trained physicians in our institutions, including many anesthesiologists. Further, there are a number of anesthesiologists that commonly utilize this tool in their daily intraoperative practice to assist in real-time management, assess the response to management and assist in guiding decision-making. This case series describes, in detail, the cardiac ultrasound examination and its ability to assist in the care for emergent noncardiac patients in the intraoperative period, potentially assisting in life-saving therapies.

\section{Methods \\ Study design}

This retrospective case series was approved by the University of Maryland School of Medicine Institutional Review Board (HP-00059760). Written informed consent was waived by the IRB. This study describes patients who received a cardiac ultrasound examination as part of their care in the intraoperative period and information retrieved from these exams. All exams were performed from January 2013 through January 2014 and were purely for diagnostic and management purposes to assist in their care by anesthesiologists.

All ultrasound examinations were performed by one of two attending anesthesiologists, both board certified in anesthesiology and critical care medicine and credentialed in critical care ultrasound. Both physicians completed accredited critical care ultrasound courses and had performed and assessed more than 150 ultrasound exams. Our institution has an established cardiac ultrasound program which has been integrated into our anesthesiology and surgery critical care fellowships. Both anesthesiologists are proficient with the cardiac ultrasound examination and participate in the education of fellows and other trainees with this transthoracic method. All examinations in this case series were done on emergent noncardiacsurgical patients with high risk of perioperative cardiac event or hemodynamic instability.

A full service portable ultrasound machine (GE Venue 40 Anesthesia, General Electric Healthcare, Waukesha, WI) was used for all cardiac ultrasound examinations, using a $3.5 \mathrm{mHz}$ phased array probe (3S).

\section{Description of the cardiac ultrasound examination}

The diagnostic cardiac ultrasound examination consisted of the four standard windows of an echocardiogram which include the parasternal long axis (PLA), parasternal short axis (PSA), apical (AP) and sub-xyphoid (SX) views. Figure 1 depicts anatomical placement of the probe and respective echocardiographic windows. The PLA is performed with the transducer just to the left of the sternum, between the $2-6^{\text {th }}$ rib interspace, depending on the location of the heart. The grove is pointed to the patient's right mid-clavicular line. This window allows for visualization of the mitral valve, aortic valve and the left ventricle. Color flow doppler is applied over the mitral and aortic valves. To obtain the PSA the probe is held in the same position and turned $90^{\circ}$, the grove is aiming at 


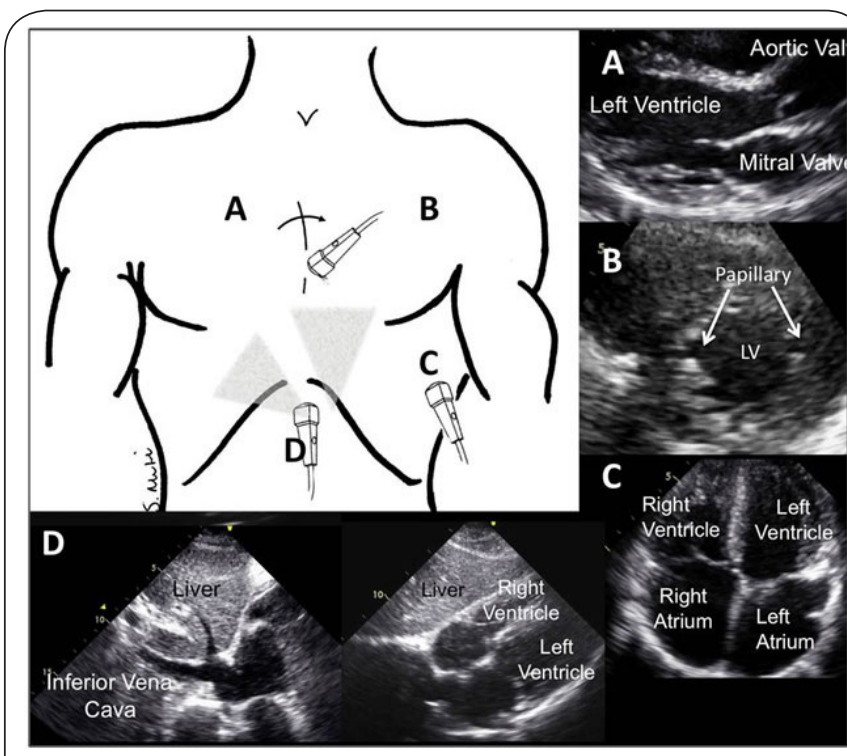

Figure 1. Four standard windows of the cardiac ultrasound examination with associated anatomical probe placement: (A) parasternal long axis [PLA], (B) parasternal short axis [PSA], (C) apical [AP] and (D) sub-xyphoid [SX] views.

the patient's left mid-clavicular line. From this window the LV and RV can be seen in short axis. Images are obtained at the aortic, mitral, papillary and apical levels of the LV. The transducer is then moved to the apex of the heart, at the $4-6^{\text {th }}$ rib interspace at the left mid-axillary line. The grove is rotated to the 3-o'clock position, and the transducer angled under the rib to obtain the 4-chamber view. The probe is then angled up to see the flow through the left ventricular outflow tract. Color flow doppler is applied across the tricuspid, mitral, and aortic valves. To obtain the SX window the transducer is moved $1-2 \mathrm{~cm}$ below the xyphoid. The grove remains in the same position, and the transducer is angled under the xyphoid to allowing visualization of the RV and pericardium. The transducer is then turned to the right and rotated grove up, to obtain the inferior vena cava (IVC) in long axis at the level of the hepatic veins. Depending on the surgical site and the availability of each of these probe positions, selected windows were performed to maintain the integrity of sterility.

Assessments were made by visual estimation using the views that were obtained. Although more advanced assessments were made at the time of assessment, this case series presents basic finding from the cardiac ultrasound examination including left ventricular function (hyperdynamic, hypodynamic or global hypokinesis) and right atrial and right ventricular function (normal or mild, moderately or severely depressed). Overall volume status and volume responsiveness was assessed and monitored by visual examination of the LV and RV at the end of diastole and systole and estimation of the inferior vena cava diameter when images were able to be obtained.

\section{Results}

This case series included six emergent noncardiac surgical patients (Table 1). Of the six patients, three were trauma, one was general surgical, one was neurosurgical and one was an orthopedic spine patient. The age range was 29 to 87 years old. There were 3 men and 3 women in the group. Three patients had the cardiac ultrasound examination performed immediately prior to induction to assess for pre-induction cardiac function, then intraoperatively for continued resuscitation management. All six patients had the cardiac ultrasound performed intraoperatively during hemodynamic instability and during real-time resuscitation. One patient had the cardiac ultrasound examination performed during an intraoperative cardiac arrest. Both experienced anesthesiologists performed the cardiac ultrasound examination with diagnostic quality images. The findings from the examinations assisted in guiding the decision-making of the anesthesiologists, specifically regarding the continuation of blood transfusions or fluid resuscitation, initiation of inotropic or vasopressor support, and assisted in the diagnosis of the etiology for hemodynamic instability and cardiac arrest.

\section{Discussion}

This case series describes the utility and feasibility of an intraoperative diagnostic cardiac ultrasound, performed by anesthesiologists, in patients undergoing emergent noncardiac surgical procedures. As ultrasound devices become more available, we surmise that this modality will continue to play a critical role in the diagnosis and management of hemodynamic instability in cardiac and noncardiac surgery. Furthermore, instituting a program to educate anesthesiologists, not specifically trained in cardiac anesthesiology or advanced TEE, to perform and interpret this simplified echocardiographic examination could increase its efficacy and utilization in the intraoperative period.Our institution continues to have a productive interdepartmental training program that has resulted in many skilled anesthesiologists currently utilizing cardiac ultrasound examinations as part of their intraoperative practice.

The main limitation of this study was the number of patients and lack of any statistical conclusions. However, this study was structured to be descriptive in nature. The methodology of the cardiac ultrasound examination and the individual case descriptions demonstrate the value of this intraoperative exam as a noninvasive hemodynamic monitor to general anesthesiologists. We describe, in detail, our protocol for performing the exam and basic assessments that were made. Further studies assessing the utility and validity of diagnostic cardiac ultrasonography in the intraoperative period may improve the strength of evidence for the indications of its use and increase its accessibility to anesthesiologists in the operating rooms. Furthermore, it may potentially impact patient management and improve emergent noncardiac surgery patient outcomes. 
Table 1. Case description of emergent noncardiac surgical patients and cardiac ultrasound examination (CUE) assessment.

\begin{tabular}{|c|c|c|c|c|c|c|c|}
\hline $\begin{array}{l}\text { Age } \\
\text { (years) }\end{array}$ & Gender & Type of surgery & $\begin{array}{l}\text { Indication for } \\
\text { CUE }\end{array}$ & $\begin{array}{l}\text { Pertinent information } \\
\text { from CUE }\end{array}$ & $\begin{array}{l}\text { Management } \\
\text { after CUE }\end{array}$ & Outcome & $\begin{array}{l}\text { Views } \\
\text { obtained }\end{array}$ \\
\hline 29 & $\mathrm{~F}$ & $\begin{array}{l}\text { Exploratory } \\
\text { Laparotomy after } \\
\text { blunt abdominal } \\
\text { trauma }\end{array}$ & $\begin{array}{l}\text { Pregnant with } \\
\text { fetal demise after } \\
\text { trauma, persistent } \\
\text { hypotension and } \\
\text { tachycardia }\end{array}$ & $\begin{array}{l}\text { Hyperdynamic LV } \\
\text { consistent with } \\
\text { hypovolemia, no wall } \\
\text { motion abnormalities }\end{array}$ & $\begin{array}{l}\text { Additional blood } \\
\text { transfusions and } \\
\text { resuscitation }\end{array}$ & $\begin{array}{l}\text { Extubated less than } 24 \\
\text { hours with full recovery }\end{array}$ & $\begin{array}{l}\text { PLA, } \\
\text { PSA, SX }\end{array}$ \\
\hline 54 & $\mathrm{M}$ & $\begin{array}{l}\text { Open reduction } \\
\text { and internal } \\
\text { fixation of open } \\
\text { right femur after } \\
\text { trauma }\end{array}$ & $\begin{array}{l}\text { Intraoperative } \\
\text { cardiac arrest }\end{array}$ & $\begin{array}{l}\text { RA and RV dilation, } \\
\text { septal flattening, no } \\
\text { thrombus seen }\end{array}$ & $\begin{array}{l}\text { Continued ACLS } \\
\text { and supportive } \\
\text { care }\end{array}$ & $\begin{array}{l}\text { Found to have a massive } \\
\text { saddle pulmonary } \\
\text { embolism, placed on } \\
\text { ECMO and received } \\
\text { a thrombectomy, } \\
\text { eventually futile. }\end{array}$ & $\begin{array}{l}\text { PLA, } \\
\text { PSA, AP }\end{array}$ \\
\hline 57 & $\mathrm{M}$ & $\begin{array}{l}\text { Cerebral } \\
\text { aneurysm } \\
\text { clipping for } \\
\text { a ruptured } \\
\text { aneurysm }\end{array}$ & $\begin{array}{l}\text { Intraoperative } \\
\text { hemodynamic } \\
\text { instability }\end{array}$ & $\begin{array}{l}\text { Global severe } \\
\text { decreased LV function, } \\
\text { adequate volume, no } \\
\text { pericardial effusion, } \\
\text { mild MR }\end{array}$ & $\begin{array}{l}\text { Initiated } \\
\text { dobutamine }\end{array}$ & $\begin{array}{l}\text { Improved hemodynamic } \\
\text { stability, dobutamine } \\
\text { weaned off within } 48 \\
\text { hours }\end{array}$ & $\begin{array}{l}\text { PLA, } \\
\text { PSA, AP }\end{array}$ \\
\hline 71 & $\mathrm{M}$ & $\begin{array}{l}\text { Exploratory } \\
\text { Laparotomy for } \\
\text { perforated viscus }\end{array}$ & $\begin{array}{l}\text { High-risk for } \\
\text { perioperative } \\
\text { cardiac event (his- } \\
\text { tory of CAD with } \\
\text { cardiac stents and } \\
\text { CABG, HTN, } \\
\text { HLD, PVD and } \\
\text { COPD) }\end{array}$ & $\begin{array}{l}\text { Decreased LV function } \\
\text { and slightly enlarge RV, } \\
\text { no pericardial effusion, } \\
\text { mild-moderate MR } \\
\text { and moderate TR }\end{array}$ & $\begin{array}{l}\text { Modified } \\
\text { induction } \\
\text { to minimize } \\
\text { vasodilation } \\
\text { and alterations } \\
\text { to cardiac } \\
\text { physiology, real- } \\
\text { time resuscitation }\end{array}$ & $\begin{array}{l}\text { Successful induction, } \\
\text { extubated }<24 \text { hours } \\
\text { postoperatively and } \\
\text { discharge } 10 \text { days later } \\
\text { to rehabilitation center }\end{array}$ & $\begin{array}{l}{ }^{*} \mathrm{PLA}, \\
\text { PSA, AP }\end{array}$ \\
\hline
\end{tabular}

${ }^{*}$ cardiac ultrasound examination also performed prior to induction

CAD: Coronary artery disease; CABG: Coronary artery bypass grafting; HTN: Hypertension; HLD: Hyperlipidemia; PVD: Peripheral vascular disease; COPD: Chronic obstructive pulmonary disease; CHF: Congestive heart failure; LV: Left ventricle; RV: Right ventricle; MR: Mitral regurgitation; TR: Tricuspid regurgitation; IVC: Inferior vena cava; ACLS: Advanced cardiovascular life support; ECMO:

Extracorporeal Membrane Oxygenation; PLA: Parasternal long axis; PSA: Parasternal short axis; AP: Apical 4-chamber; SX: Sub-xyphoid

\section{Competing interests}

The authors declare that they have no competing interests.

\section{Authors' contributions}

\begin{tabular}{|l|c|c|c|}
\hline Authors' contributions & CMH & SMG & SBM \\
\hline Research concept and design & $\checkmark$ & $\checkmark$ & $\checkmark$ \\
\hline Collection and/or assembly of data & $\checkmark$ & $\checkmark$ & $\checkmark$ \\
\hline Data analysis and interpretation & $\checkmark$ & $\checkmark$ & -- \\
\hline Writing the article & $\checkmark$ & $\checkmark$ & $\checkmark$ \\
\hline Critical revision of the article & $\checkmark$ & -- & -- \\
\hline Final approval of article & $\checkmark$ & $\checkmark$ & $\checkmark$ \\
\hline
\end{tabular}

\section{Publication history}

Editor: Gerald A. Bushman, Childrens Hospital Los Angeles, USA. EIC: D. John Doyle, Case Western Reserve University, USA. Received: 15-Oct-2015 Final Revised: 18-Nov-2015 Accepted: 24-Nov-2015 Published: 04-Dec-2015

\section{References}

1. Mangano DT. Perioperative cardiac morbidity. Anesthesiology. 1990; 72:153-84. | Article | PubMed

2. Matulevicius SA, Rohatgi A, Das SR, Price AL, DeLuna A and Reimold SC. Appropriate use and clinical impact of transthoracic echocardiography. JAMA Intern Med. 2013; 173:1600-7. | Article | PubMed 
3. Shillcutt SK, Markin NW, Montzingo CR and Brakke TR. Use of rapid "rescue" perioperative echocardiography to improve outcomes after hemodynamic instability in noncardiac surgical patients. J Cardiothorac Vasc Anesth. 2012; 26:362-70. | Article | PubMed

4. Schulmeyer MC, Santelices E, Vega R and Schmied S. Impact of intraoperative transesophageal echocardiography during noncardiac surgery. J Cardiothorac Vasc Anesth. 2006; 20:768-71. | Article | PubMed

5. Schulmeyer C, Farias J, Rajdl E, de La Maza J and Labbe M. Utility of transesophageal echocardiography during severe hypotension in non-cardiac surgery. Rev Bras Anestesiol. 2010; 60:513-21. | Article | PubMed

6. Ng A and Swanevelder J. Perioperative echocardiography for noncardiac surgery: what is its role in routine haemodynamic monitoring? Br J Anaesth. 2009; 102:731-4. | Article | PubMed

7. Patteril $M$ and Swaminathan M. Pro: intraoperative transesophageal echocardiography is of utility in patients at high risk of adverse cardiac events undergoing noncardiac surgery. J Cardiothorac Vasc Anesth. 2004; 18:107-9. | Article | PubMed

8. Hofer CK, Zollinger A, Rak M, Matter-Ensner S, Klaghofer R, Pasch T and Zalunardo MP. Therapeutic impact of intra-operative transoesophageal echocardiography during noncardiac surgery. Anaesthesia. 2004; 59:3-9. | Article | PubMed

9. Lennon MJ, Gibbs NM, Weightman WM, Leber J, Ee HC and Yusoff IF. Transesophageal echocardiography-related gastrointestinal complications in cardiac surgical patients. J Cardiothorac Vasc Anesth. 2005; 19:141-5. | Article | PubMed

10. Mahajan A and Ebadi A. Clinical Utility of Transesophageal Echocardiography in Noncardiac Surgery. Seminars in Anesthesia, Perioeprative Medicine and Pain. 2003; 22:106-18.

11. Andrus BW and Welch HG. Medicare services provided by cardiologists in the United States: 1999-2008. Circ Cardiovasc Qual Outcomes. 2012; 5:31-6. | Article | PubMed

12. Cowie B. Focused cardiovascular ultrasound performed by anesthesiologists in the perioperative period: feasible and alters patient management. J Cardiothorac Vasc Anesth. 2009; 23:450-6. I Article | PubMed

13. Canty DJ and Royse CF. Audit of anaesthetist-performed echocardiography on perioperative management decisions for noncardiac surgery. Br J Anaesth. 2009; 103:352-8. | Article | PubMed

14. Geisen M, Spray D and Nicholas Fletcher S. Echocardiography-based hemodynamic management in the cardiac surgical intensive care unit. J Cardiothorac Vasc Anesth. 2014; 28:733-44. | Article | PubMed

15. Maybauer MO, Asmussen S, Platts DG, Fraser JF, Sanfilippo F and Maybauer DM. Transesophageal echocardiography in the management of burn patients. Burns. 2014; 40:630-5. | Article | PubMed

16. Oren-Grinberg A, Talmor D and Brown SM. Focused critical care echocardiography. Crit Care Med. 2013; 41:2618-26. | Article | PubMed Abstract | PubMed Full Text

17. Narasimhan M, Koenig SJ and Mayo PH. Advanced echocardiography for the critical care physician: part 1. Chest. 2014; 145:129-34. | Article | PubMed

18. Narasimhan M, Koenig SJ and Mayo PH. Advanced echocardiography for the critical care physician: part 2. Chest. 2014; 145:135-42. | Article | PubMed

19. Ferrada P, Murthi S, Anand RJ, Bochicchio GV and Scalea T. Transthoracic focused rapid echocardiographic examination: real-time evaluation of fluid status in critically ill trauma patients. J Trauma. 2011; 70:56-62. | Article I PubMed

20. Murthi SB, Hess JR, Hess A, Stansbury LG and Scalea TM. Focused rapid echocardiographic evaluation versus vascular cather-based assessment of cardiac output and function in critically ill trauma patients. J Trauma Acute Care Surg. 2012; 72:1158-64. | Article | PubMed

21. Cowie BS. Focused transthoracic echocardiography in the perioperative period. Anaesth Intensive Care. 2010; 38:823-36. | Pdf | PubMed
Citation:

Hong CM, Galvagno SM and Murthi SB. The use of ultrasound-guided cardiac assessment in the anesthetic management for emergent noncardiac surgical patients. J Anesthesiol Clin Sci. 2015; 4:7. http://dx.doi.org/10.7243/2049-9752-4-7 